\title{
An Empirical Model of Students Satisfaction and Service Quality of Jahangirnagar University
}

\section{Moyazzem Hossain}

\author{
Department of Statistics Jahangirnagar University, Savar, Dhaka, Bangladesh \\ hossainmm@juniv.edu
}

\begin{abstract}
Satisfaction is a state felt by a person who has experienced performance or an outcome that fulfill his or her expectation and service quality is an important parameter of educational excellence. This study attempts to examine the relationship between service quality dimensions (tangibility, responsiveness, reliability, assurance and empathy) and students' satisfaction. The results exhibit that there is a significant correlation among all the constructs with student satisfaction at $1 \%$ level of significance. The results also depict that the tangibles factor is the most important factor which includes a group of statements related to the environment and facilities provided by the university. Therefore, this paper will be helpful for institutions in order to enhance the quality of educational services.
\end{abstract}

Keywords: Student's Satisfaction; Service Quality; Factor Analysis; Bangladesh

\section{Introduction}

Student satisfaction has become a major challenge for the universities and it has been recognized that student satisfaction is the major source of competitive advantage and this satisfaction also leads towards student retention, attraction for new students and positive word of mouth communication, as well (Arambewela \& Hall [1]). Aly and Akpovi [2] and Kanji et al., [3] pointed out that the long-term survival and success of the universities depending upon the quality of services and the effort made by them to achieve that distinguishes one university from other universities. Now, the concept of quality and customer satisfaction had been evolved in educational sector and got considerable attentions (Ana Brochado [4]). These trends have also been seen in the developing countries like Bangladesh.

Universities must continually assess their service. Outstanding service quality as perceived by the customer, can give any organization a competitive advantage (Albrecht [5]). Therefore, perceived service quality could be the product of the evaluations of a number of service encounters and in this case, of a student, these could range from encounters with office staff, to encounters with tutors, lecturers, the head of departments, etc. (Hill [6]). As a result, if an organization regularly provides service at a level that exceeds customer expectations, the service will be evaluated as high quality.

Generally, students have three main criteria that need to be satisfied with services. These has been labeled as Requisite encounters which essentially enable students to fulfill their study obligations; Acceptable encounters which students acknowledge as being desirable but not essential during their course of study and Functional, an encounter of a practical or utilitarian nature (Oldfield and Baron [7]). According to Lassar, et al., [8], two most prevalent and widely accepted perspectives on service quality include the SERVQUAL model. Parasuraman, et al., [9] however listed ten determinants of service quality that can be generalized to any type of service. The ten dimensions include tangibility, reliability, responsiveness, competence, access, courtesy, communication, credibility, security and understanding. In addition, these ten dimensions were then regrouped in the well-known five dimensions in the SERVQUAL model (Parasuraman et al., [10]) which include assurance, empathy, reliability, responsiveness and tangibility. Asaduzzaman, et al., [11] used SERVQUAL model to analyze the service quality and student's satisfaction of the private university students in Bangladesh. ljaz et al. [12] used a modified SERVQUAL instrument to evaluate the service quality of four business schools working under public sector universities based on student perceptions. Based upon the present context of service quality in the higher education sector of Bangladesh, the main objectives of this study are to examine the relationship between service quality dimensions (tangibility, responsiveness, reliability, assurance, empathy and overall service quality) 
and students' satisfaction of Mathematical and Physical Sciences faculty of Jahangirnagar University in Bangladesh.

\section{Methodology}

This study was adopted from Parasuraman's SERVQUAL dimensions. The dependent variable in this study is overall student satisfaction. The independent variable in this study is service quality in higher education that measures the level of satisfaction with service performance. The dimensions included in this variable are tangibility, assurance, responsiveness, reliability, and empathy. The students of the Mathematical and Physical Sciences faculty of the Jahangirnagar University of Bangladesh was the respondents for this study. A sample of 280 students is chosen by a stratified random sampling based on the level of study and gender. The required primary data was collected by a well-trained team consisted of five graduate students of Statistics department. Firstly, the author of this paper has conducted a training session on the data collection procedures. Then they involve in data collection by a face-to-face interview with the students from different departments. The data collection period was from December, 2017 to January, 2018. However, the whole data collection procedure is also supervised by a team leader who continuously contacts with the authors of this paper. A well-structured questionnaire is employed to collect the primary data. This questionnaire has two parts. The first section of the questionnaire contains the demographic and basic characteristics of the respondents. However, the final part contains the questions related to the student's satisfaction and service quality of the university. Hence, most of the questions have the 5 -point Likert scale ( 1 is used for Strongly disagree and 5 for strongly agree) format since the consistent use of the Likert scale format in the questionnaire is a good way to easily collect and code the data. The collected data were then analyzed by SPSS version 22. The location map of the study area for this study is presented in Figure 1.

\section{Results and Discussion}

Reliability of the data was checked using Cronbach Alpha which provides a value of 0.898 is more than the acceptable value of 0.70 (Nunnally [13]; Hair et al., [14]; Zikmund [15]) and a value ranges between 0 and 1 and the value close to 1 provides more reliability (Nunnally and Bernstein [16]).

Frequency distribution of the demographic characteristics of the variables considered in this study is reported in Table 1. The participants of this study are the male and female students. Almost three-fifths of the respondents were male, whereas the female respondents were 103 (36.8\%). However, approximately 95 percent of the respondents are undergraduate students. Majority of the student was less than 23 years of age and only $10 \%$ of the student was above 23 years of age. Also, almost equal number of students were taken from each of the department from the faculty of mathematical and physical science faculty of Jahangirnagar University. 


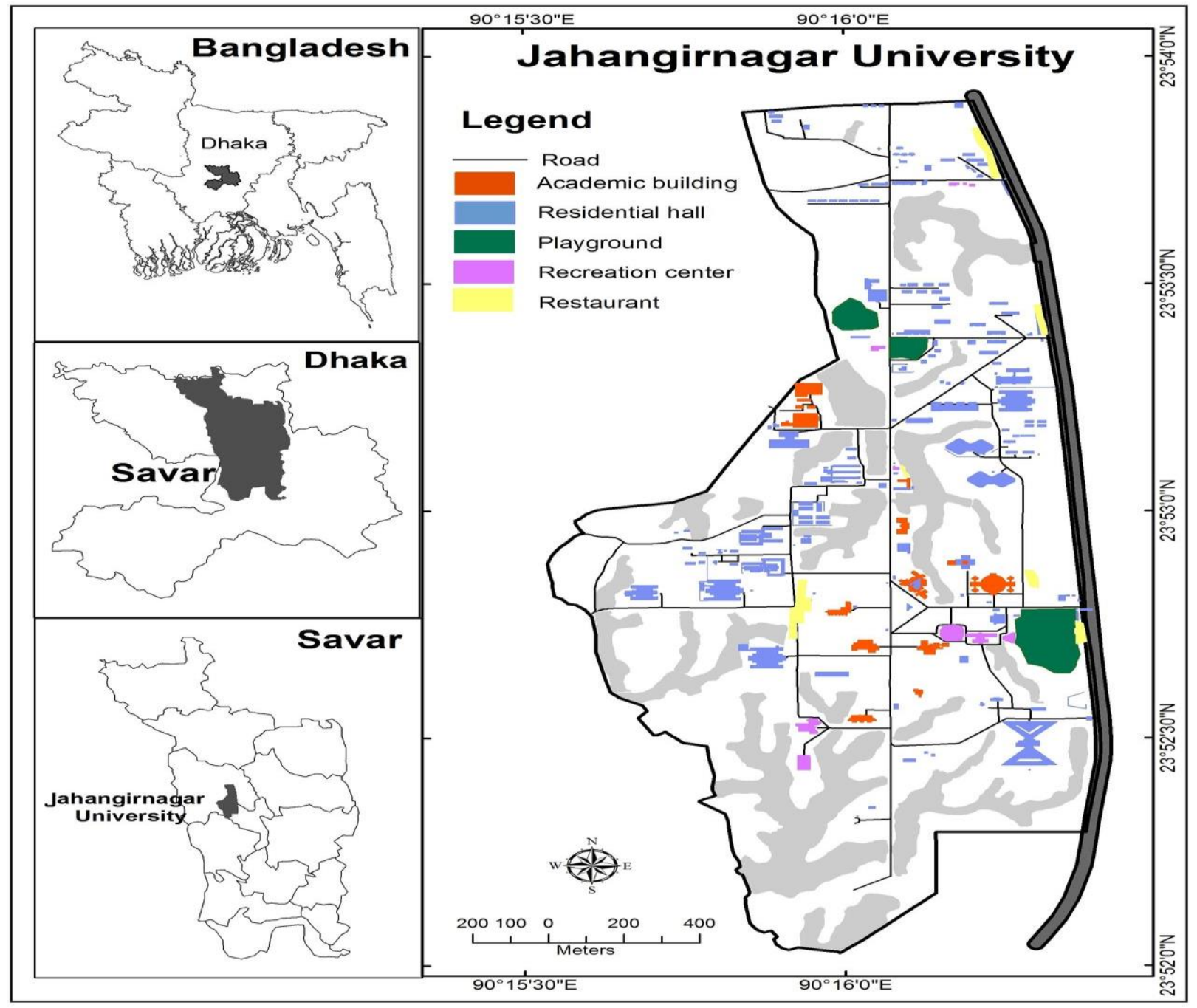

Figure 1: Location Map of the study area

Table 1: Frequency Distribution of the Demographics Characteristics

\begin{tabular}{|c|c|c|c|c|c|}
\hline Gender & Frequency & Percentage & Departments & Frequency & Percentage \\
\hline Male & 177 & 63.2 & $\begin{array}{l}\text { Computer Science and } \\
\text { Engineering (CSE) }\end{array}$ & 30 & 10.7 \\
\hline Female & 103 & 36.8 & Physics & 40 & 14.3 \\
\hline Total & 280 & 100 & Chemistry & 40 & 14.3 \\
\hline \multicolumn{3}{|c|}{ Marital Status } & Statistics & 50 & 17.9 \\
\hline Single & 263 & 93.9 & Mathematics & 50 & 17.9 \\
\hline Married & 17 & 6.1 & Environmental Science & 35 & 12.5 \\
\hline Total & 280 & 100 & Geological Science & 35 & 12.5 \\
\hline
\end{tabular}




\begin{tabular}{|c|c|c|c|c|c|}
\hline \multicolumn{3}{|c|}{ Academic Year } & Total & 280 & 100 \\
\hline First Year & 96 & 34.3 & Age & & \\
\hline Second Year & 77 & 27.5 & $\leq 20$ & 107 & 38 \\
\hline Third Year & 68 & 24.3 & $20-23$ & 144 & 51 \\
\hline Fourth Year & 26 & 9.3 & $23-26$ & 29 & 10 \\
\hline Masters & 13 & 4.6 & Total & 280 & 100 \\
\hline Total & 280 & 100.0 & & & \\
\hline
\end{tabular}

Table 2 represents the descriptive statistics of the academic results of the selected students by different years. It is observed that except for the first year the average Cumulative Grade Point Average (CGPA) of the respondents are near about 3.5 out of 4.0 scale. In case of the first year, the minimum CGPA is 2.80 and maximum 3.80. However, in case of the third and fourth year the minimum CGPA is exactly 3.0 and for the second year, it is approximately 3.0. The maximum CGPA for the first, second, third and fourth year are 3.80, 3.90, 3.83 and 3.85 respectively.

Table 2: Descriptive statistics of the respondent's academic results (CGPA)

\begin{tabular}{|l|c|c|c|c|}
\hline Statistic & First Year & Second Year & Third Year & Fourth Year \\
\hline Mean & 3.38 & 3.40 & 3.43 & 3.44 \\
\hline Standard Deviation & 0.22 & 0.22 & 0.23 & 0.30 \\
\hline Kurtosis & -0.67 & -0.35 & -0.56 & -0.82 \\
\hline Skewness & -0.23 & 0.02 & -0.35 & 0.00 \\
\hline Minimum & 2.80 & 2.96 & 3.00 & 3.00 \\
\hline Maximum & 3.80 & 3.90 & 3.83 & 3.85 \\
\hline
\end{tabular}

Table 3 depicts the correlation between the five service quality dimensions i.e., tangibles, reliability, responsiveness, assurance, empathy and student satisfaction. Modal value of all the constructs was calculated and taking the average and then find the correlation among the constructs of the independent variables. The data shows that here all the correlation coefficients are statistically significant at 1 percent level of significance. The highest correlation (0.806) is observed between satisfaction and reliability of the institution which indicates that the reliability of the institution plays a significant role while selecting the institution for the study and it also has a significant impact on student satisfaction. However, the weakest correlation is observed among student satisfaction and empathy which is 0.426 . 
Table 3: Correlation among service quality dimensions and student satisfaction

\begin{tabular}{|l|c|c|c|c|c|c|}
\hline Variable & $\begin{array}{l}\text { Overall } \\
\text { satisfaction }\end{array}$ & Tangibles & Reliability & Responsiveness & Assurance & Empathy \\
\hline Overall satisfaction & 1 & & & & & \\
\hline Tangibles & $0.624^{* *}$ & 1 & & & & \\
\hline Reliability & $0.806^{* *}$ & $0.499^{\star *}$ & 1 & & & \\
\hline Responsiveness & $0.691^{* *}$ & $0.446^{* *}$ & $0.636^{* *}$ & 1 & & \\
\hline Assurance & $0.632^{* *}$ & $0.419^{* *}$ & $0.568^{* *}$ & $0.613^{* *}$ & 1 & \\
\hline Empathy & $0.426^{* *}$ & $0.372^{* *}$ & $0.362^{* *}$ & $0.312^{* *}$ & $0.357^{* *}$ & 1 \\
\hline
\end{tabular}

${ }^{* *}$ Correlation is significant at the 0.01 level (2-tailed).

Here, the factor analysis based on the principle component analysis method is used to identify the most important factors that have a contribution to the satisfaction. Firstly, the Scree plot is used to determine the tentative number of factors. It can be seen from the graph provided in Figure 2 that five or six factors may be useful for this analysis. However, the eigenvalue is finally used to identify the number of factors.

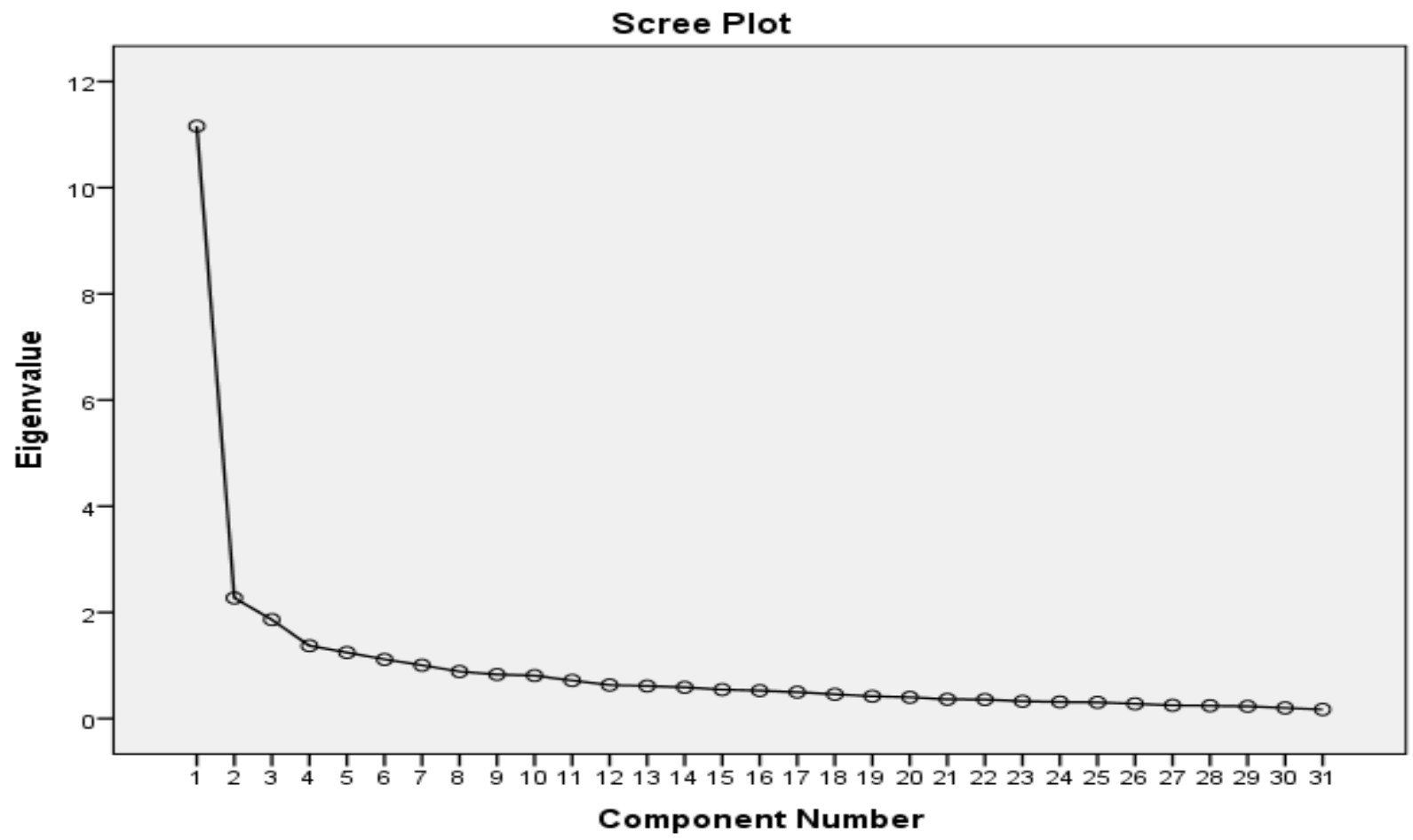

Figure 2: Scree plot

The factor loadings of five identified dimensions/factors (Factor 1 stands for tangibles, Factor 2 is for reliability, Factor 3 is used for Responsiveness, Assurance is labeled by Factor 4 and finally Factor 5 is used to indicate

Empathy) are presented in Table 4, and among the factors, Factor 1 is the most important since it is accounting for the largest proportion of the variance (36 percent), with eigenvalues greater than 3.00 (11.158). 
This factor includes a set of statements related to the environment and facilities provided by the university and is labeled as 'tangibles'.

Table 4: Results of Factor Analysis

\begin{tabular}{|c|c|c|c|c|c|}
\hline & \multicolumn{5}{|c|}{ Factors } \\
\hline & 1 & 2 & 3 & 4 & 5 \\
\hline \multicolumn{6}{|l|}{ Factor 1: Tangibles } \\
\hline Lighting in class room is very nice & 0.465 & & & & \\
\hline Appearance of building and ground is nice & 0.393 & & & & \\
\hline Overall cleanliness & 0.549 & & & & \\
\hline Temperature of class room and study room are comfortable & 0.484 & & & & \\
\hline Decoration and atmosphere & 0.629 & & & & \\
\hline Appearance of personnel is good & 0.556 & & & & \\
\hline Available of parking & 0.412 & & & & \\
\hline Computer adequacy provided in lab & 0.458 & & & & \\
\hline Access to the internet & 0.539 & & & & \\
\hline \multicolumn{6}{|l|}{ Factor 2: Reliability } \\
\hline Registration is timely and error free & & 0.472 & & & \\
\hline University keeps records accurately & & 0.632 & & & \\
\hline Classes take regularly & & 0.636 & & & \\
\hline Staffs are sincere to solve student's problem & & 0.709 & & & \\
\hline Provide service in time & & 0.749 & & & \\
\hline Teaching capability of teachers are well & & 0.705 & & & \\
\hline Academic staffs are interested to solve student's problems & & 0.734 & & & \\
\hline \multicolumn{6}{|l|}{ Factor 3: Responsiveness } \\
\hline Availability of personnel to assist you & & & 0.622 & & \\
\hline Availability of teachers to assist you & & & 0.751 & & \\
\hline Teachers have capacity to solve immediate problems & & & 0.751 & & \\
\hline
\end{tabular}




\section{Factors}

$\begin{array}{lllll}1 & 2 & 3 & 4 & 5\end{array}$

Staffs have capacity to solve immediate problem

0.601

Channels are available for complains

Queries are deal with efficiently

Factor 4: Assurance

Staffs are friendly

Teachers are friendly

Teachers are efficient for research

Staffs has knowledge of university rules and responsibility

University has enough security

Factor 5: Empathy

University administration has student-based interest

Computer facility for students is sufficient

Study rooms are available for students

Staffs are willing to give students individual attention

Eigenvalue

$11.158 \quad 2.271$

1.864

1.371

1.004

Explained variance by factor (\%)

$\begin{array}{llll}35.995 & 10.923 & 7.012 & 6.439\end{array}$

4.240

Extraction Method: Principal Component Analysis, Rotation Method: Varimax with Kaiser Normalization, Rotation converged in 9 iterations.

However, the remaining four factors did not reach eigenvalues of 3.00, and the percentages of the variance together only account for 28 percent of the total. The second factor is labeled as 'reliability'. This factor includes the statements related to the activities of a lecturer (teaching staffs) e.g., his or her intrinsic role as a teacher, willing to guide, teach and motivate students. The variables included in this factor also provide evidence of the responsibilities of a lecturer towards the students in terms of providing the clear guidelines, precise and prompt response and private consultation. Moreover, Factor 3 includes six items relate to the adequate provision of services by the university and hence are labeled here 'responsiveness' and all the items have loadings, ranging from 0.601 to 0.751 and explains approximately 7 percent of the common variance. Furthermore, Factor 4 is labeled 'assurance' and it includes five items and they only explain 6.44 percent of the common variance. The final factor contains four items and all the items have loadings, ranging from 0.443 to 0.555 and they only explain 4.24 percent of the common variance. 
The institutions considered in the study in order to enhance the quality of educational services as well as update the curricula according to the requirements of local global demands. These Institutions need to develop and implement quality standards and system and continuously monitor it in order to increase the quality of education and gain a competitive edge on rapidly growing institutes in Bangladesh. Due to the small sample size, the results of this study cannot be generalized. However, a more comprehensive study can be conducted by taking a larger sample size and including all the educational institutions in the country to develop a comprehensive service quality and student satisfaction model.

\section{Conclusion}

Although measuring the quality of services based on customer perceptions is a complex task, however, to some extent we can get a little understanding about the quality of services provided by the service providers. The concept of quality has also been recognized in the services sector and now the universities are also concentrating and making efforts to gain student satisfaction by delivering quality of teaching and non-teaching services (Petruzzellis et al., [17]).

Almost three-fifth of the respondents were male, whereas the female respondents were 103 (36.8\%). However, approximately 95 percent of the respondents are undergraduate students. Majority of the student were less than 23 years of age and only $10 \%$ of the student was above 23 years of age. It is observed that except first year the average results of the respondents are near about 3.5 out of 4.0 scale. In case first year the minimum GPA is 2.80 and maximum 3.80. However, the maximum GPA for first, second, third and fourth year are 3.80, 3.90, 3.83 and 3.85 respectively. There is a significant correlation among all the constructs with student satisfaction and also among each other at 0.01 significant levels. However, highest correlation between satisfaction and reliability of the institution which is $80.6 \%$, which indicates reliability of the institution plays a significant role while selecting the institution for study and it also has a significant impact on student satisfaction. The weakest correlation among student satisfaction and empathy is $42.6 \%$. Factor 1 is by far the most important, accounting for the largest proportion of the variance (34 per cent), with eigenvalues greater than 3.00 (11.158). This factor includes a group of statements related to environment and facilities of the university, and is labeled here 'tangibles'.

The institutions considered in the study have to make continuous efforts to enhance quality of educational services, update the curricula according to the local industry requirements and also the global acceptability. These Institutions need to develop and implement quality standards and system and continuously monitor it in order to increase the quality of education and gain competitive edge on rapidly growing institutes in Bangladesh. Due to small sample considered in this study, the results of this study cannot be generalized. However, a more comprehensive study can be conducted by taking a larger sample size and including all the educational institutions in the country to develop a comprehensive service quality and student satisfaction model.

\section{Acknowledgements}

Authors are grateful to the Jahangirnagar University for providing the financial support in order to conduct this research as well as permission to publish in the journal. The authors also would like to give thanks to Sahadat Hossain, Department of Public Health and Informatics, Jahangirnagar University, Bangladesh for supporting to prepare the location map of the study area. 


\section{References}

1. Arambewela, R. and John Hall, "An empirical model of international student satisfaction," Asia Pacific Journal of Marketing and Logistics, Vol. 21, No. 4, 2009, pp. 555-569.

2. Aly, N. and Akpovi, J., "Total quality management in California public higher education," Quality Assurance in Education, Vol. 9, No. 3, 2001, pp. 127-31.

3. Kanji, G.K., Malek, A. and Tambi, A., "Total quality management in UK higher education institution," Total Quality Management, Vol. 10, No. 1, 1999, pp. 129-53.

4. Ana Brochado, "Comparing alternative instruments to measure service quality in higher education," Quality Assurance in Education, Vol. 17, No. 2, 2009, pp. 174-190.

5. Albrecht, K., "Total Quality Service," Executive Excellence, July, 1991, pp. 18-19.

6. Hill, F. M., "Managing service quality in higher education: the role of the student as primary consumer," Quality Assurance in Education, Vol. 3, No. 3, 1995, pp. 10-21.

7. Oldfield, B. and Baron, S., "Student Perceptions of Service Quality in a UK University Business and Management Faculty," Quality Assurance in Education, Vol. 8, 2000, pp. 85-95.

8. Lassar, W. M., Manolis, C., and Winsor, R. D., "Service quality perspectives and satisfaction in private banking," Journal of Service Marketing, Vol. 14, No. 3, 2000, pp. 244-271.

9. Parasuraman, A., Zeithaml, V. and Berry, L. L., "A conceptual model of service quality and its implications for future research," Journal of Marketing, Vol. 49, Autumn, 1985, pp. 41-50.

10. Parasuraman, A., Zeithaml, V. A. and Berry, L. L., "Five imperatives for improving service quality," Sloan Management Review, 1990, pp. 29-38.

11. Asaduzzaman, Moyazzem Hossain, Mahabubur Rahman, Service Quality and Student Satisfaction: A Case Study on Private Universities in Bangladesh, International Journal of Economics, Finance and Management Sciences. Vol. 1, No. 3, 2013, pp. 128-135. doi: 10.11648/j.jijefm.20130103.11

12. A. Ijaz, S.M. Irfan, S. Shahbaz, M. Awan, and M. Sabir, "An Empirical Model of Student Satisfaction: Case of Pakistani Public Sector Business Schools," Journal of Quality and Technology Management, Vol. 7, No. 2, 2011, pp. $91-114$.

13. Nunnally, J. C., "Psychometric Theory," 2nd ed., McGraw-Hill, New York, NY, 1978.

14. Hair, J. R., Anderson, R. E., Tatham, R. L. and Black, W. C., "Multivariate Data Analysis," 8th ed., PrenticeHall International, Englewood Cliffs, NJ, 2006.

15. Zikmund, W.G., "Essentials of Marketing Research," The Dryden Press, Harcourt Brace College Publishers, Hinsdale, IL, 1998.

16. Nunnally, J. C., and Bernstein, I. H., "Psychometric Theory," 3rd ed., New York: McGraw-Hill, 1994.

17. Petruzzellis Luca, Angela Maria D'Uggento and Salvatore Romanazzi, "Student satisfaction and quality of service in Italian universities," Managing Service Quality, Vol. 16 No. 4, 2006, pp. 349-364. 